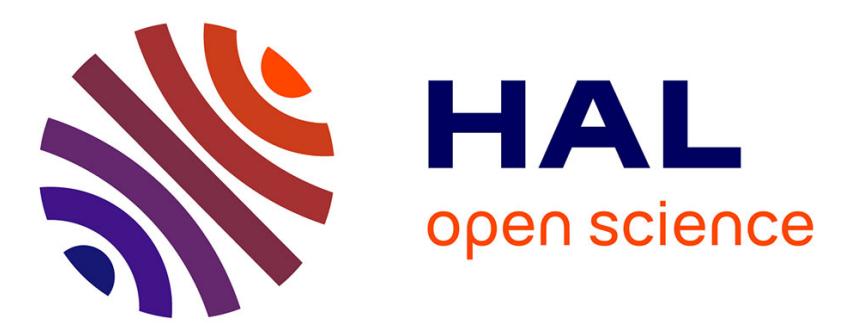

\title{
A supplier selection model: A Comparison of Fuzzy Logic and the Analytic Hierarchy Process
}

\author{
Ashraf W Labib
}

\section{To cite this version:}

Ashraf W Labib. A supplier selection model: A Comparison of Fuzzy Logic and the Analytic Hierarchy Process. International Journal of Production Research, 2011, pp.1. 10.1080/00207543.2010.531776 . hal-00664002

\section{HAL Id: hal-00664002 https://hal.science/hal-00664002}

Submitted on 28 Jan 2012

HAL is a multi-disciplinary open access archive for the deposit and dissemination of scientific research documents, whether they are published or not. The documents may come from teaching and research institutions in France or abroad, or from public or private research centers.
L'archive ouverte pluridisciplinaire HAL, est destinée au dépôt et à la diffusion de documents scientifiques de niveau recherche, publiés ou non, émanant des établissements d'enseignement et de recherche français ou étrangers, des laboratoires publics ou privés. 


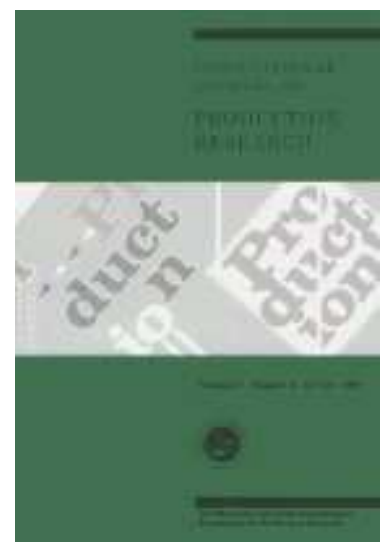

\section{A supplier selection model: A Comparison of Fuzzy Logic and the Analytic Hierarchy Process}

\begin{tabular}{|r|l|}
\hline Journal: & International Journal of Production Research \\
\hline Manuscript ID: & TPRS-2010-IJPR-0406.R1 \\
\hline Manuscript Type: & Original Manuscript \\
\hline $\begin{array}{r}\text { Date Submitted by the } \\
\text { Author: }\end{array}$ & 06-Sep-2010 \\
\hline Complete List of Authors: & $\begin{array}{l}\text { Labib, Ashraf W; The University of Portsmouth, Dept of Strategy } \\
\text { and Business Systems }\end{array}$ \\
\hline Keywords: & SUPPLIER SELECTION, SUPPLY CHAIN MANAGEMENT, FUZZY LOGIC \\
\hline Keywords (user): & Analytical Hierarchy Process \\
\hline &
\end{tabular}

\section{SCHOLARONE}

Manuscripts 


\title{
A supplier selection model: A Comparison of Fuzzy Logic and the Analytic Hierarchy Process
}

\author{
Ashraf W. Labib \\ University of Portsmouth, Portsmouth Business School, Richmond Building, Portland Street, \\ Portsmouth PO1 3DE, United Kingdom

\section{Ashraf.Labib@port.ac.uk}

\begin{abstract}
:
This paper aims to compare two tools for decision makers that intend to support the decision of the selection of the appropriate supplier. Suppliers are crucial to both the efficiency and effectiveness of the performance of Companies. A critical success factor of these companies is the selection of the appropriate supplier. A methodology is proposed to optimise the evaluation process based on different criteria. The proposed approach extends the one proposed by Ordoobadi (2009) who proposed the application of Fuzzy Logic (FL) where we use the same example case study in order to compare the Analytic Hierarch Process (AHP) with FL.
\end{abstract}

In this paper we demonstrate how we can achieve the same objective of expressing human assessments in the form of linguistic expressions by using AHP. Moreover, we demonstrate the capability to run a sensitivity analysis which helps to understand the causal relationships among the different factors. We demonstrate how this capability can help us to explain and predict the different relationships among criteria and alternatives. Moreover, we provide a measure that is able to capture the consistency of the decision maker's preferences. In our approach we provide a single unit of scale that is not only capable of ranking suppliers but also provides an understanding of the difference in scale between different suppliers which can then help to allocate resources accordingly. These facilities are not offered by Ordoobadi (2009). The proposed approach here can help companies to identify the best supplier in changing environments. The paper describes a decision model that incorporates decision maker's subjective assessments and applies multiple criteria decision making technique to manipulate and quantify these assessments. Unlike many similar studies, two techniques have been performed on the same case study in order to improve our understanding of the differences in the proposed techniques.

\section{Background and Motivation:}

In recent literature, the supplier selection problem has been studied by many authors. For example, authors in this journal who have investigated supplier selection include; Chan etal (2008), Sevkli etal (2007), Jain etal (2007), Lee and Yang (2008), Kannan and Haq (2007), Yao etal (2010), Sen etal (2010), Liu and Zhang (2010), Ravindran etal (2010), Talluri etal (2010), and Che (2009). The authors of those papers have either proposed a certain method such as fuzzy logic, multiple criteria using for example the analytic hierarchy process (AHP), or genetic algorithms, but none have compared the same application using a hybrid of techniques. In this paper a comparison of both AHP and fuzzy logic is performed for the same case study and hence it illustrates the applicability of both methods. For a comprehensive account of the evolution of supplier selection criteria and methods, see (Zhang etal, 2003), and (Ho, etal, 2010). 
In an article by Ordoobadi (2009), she provides a comprehensive list of developed models that focus on the identification of supplier attributes and then using various techniques for evaluation of these attributes. Ordoobadi then argues that a common feature among these techniques is how the rankings of the potential suppliers are determined and that most often these rankings are assigned based on two factors: the importance weight of the attributes, and suppliers' performance with respect to these attributes. Both of these factors are decision maker-specific and thus should be solicited from the individuals. Often elicitation process is conducted by asking the decision makers to express their preferences in pure numeric scales. Ordoobadi then claims that the main difficulty with such an elicitation procedure is that the subjectivity and imprecision associated with perceptions are lost by forcing the decision makers to use numeric scales. She then proposes a method to overcome the above mentioned difficulty through a mechanism that captures the subjectivity involved in expressing individual preferences. Ordoobadi proposes fuzzy logic as a methodology that allows the decision maker to express preferences in linguistic terms.

Briefly, the proposed evaluation by Ordoobadi (2009) is performed based on the importance of the selection criteria to the decision maker as well as his/her perception of the supplier's performance with respect to these criteria. Using fuzzy membership functions and fuzzy mathematical operators a fuzzy score is determined for each supplier. These fuzzy scores are then converted to crisp values through defuzzification process to make the ranking of the suppliers a straightforward task. The supplier with the highest ranking is selected.

\section{[Table I here]}

[Figure 1 here]

[Table II here]

[Table III here]

The proposed approach of using Fuzzy Logic (FL) in the case study provided by Ordoobadi (2009) whilst able to capture the subjectivity involved in expressing individual preferences, it just provides the ranking of the three suppliers A, B, and C. The scale used to determine the crisp score does not say much about how close, or far, they are from each other. There is no way of identifying how the different factors affect the final score. For example what happens if the importance of one of the factors is changed?

[Table IV here]

The rest of the paper is organized as follows: A brief overview of the analytic hierarchy process (AHP) theory and as well as a review of its applications are provided in section 2. Section 3 covers the development of the evaluation methodology. A numerical example is 
provided in section 4 to illustrate the application of the proposed model. We use the same example provided by Ordoobadi (2009) in order to provide a comparison of the two methods. Finally the paper concludes with summary and suggestions for future research in section 5 .

\section{A brief overview of the analytic hierarchy process (AHP):}

The Analytic Hierarchy Process (AHP) is a multi-criteria decision making (MCDM) method that helps the decision-maker facing a complex problem with multiple conflicting and subjective criteria such as location or investment selection, projects ranking, and so forth (Ishizaka and Labib 2009).

The AHP is designed to solve complex decision-making problems when there are multiple objectives or criteria to consider. This approach has been introduced by Saaty (1977, 1980 and 1994) and requires the decision maker(s) to provide judgements about the relative importance of each criterion and then specify a preference on each criterion for each decision alternative. It has also been applied in many industrial cases and combined with other techniques such as the work done by Vassoulla etal (2006), Abdi and Labib (2003, 2004), Davidson and Labib (2003), Alvi and Labib (2001) and Labib and Shah (2001).

According to Vassoulla etal (2006) the first step in the AHP is the decomposition of the problem into a decision hierarchy. This may take the form illustrated in Figure 2.

\section{[Figure 2: here]}

The next step is to establish priorities amongst the elements in the hierarchy by making pairwise comparisons of the criteria and alternatives. Given Criterion $i$ and Criterion $j$, these comparisons are carried out using Saaty's (1980) predefined one-to-nine ratio scale as listed in Table V.

\section{[Table V here]}

The pairwise comparisons are carried out for all factors to be considered and the $\mathrm{n} \times \mathrm{n}$ positive reciprocal matrix $A$ is generated for $C_{1}, \ldots, C_{n}, n \geq 2$ criteria, with elements $\alpha_{i j}$, indicating the value of the criterion $i$ relative to criterion j. Where $\alpha_{i i}=1$ (i.e. on the diagonal) and if $\alpha_{i j}=\mathrm{k}$, then $\alpha_{j i}=1 / \mathrm{k}$ (reciprocity property). 
Approximating the weight vector of the above matrix $A$, with $n$ objectives, takes the form illustrated below. Where $w_{i}>0, i=1, \ldots . ., n$, denotes the weight of objective $i$. The next step is the calculation of a list of the relative weights of the criteria under consideration. This requires to normalise each column $j$ in A such that $\sum_{j} a_{i j}=1$.

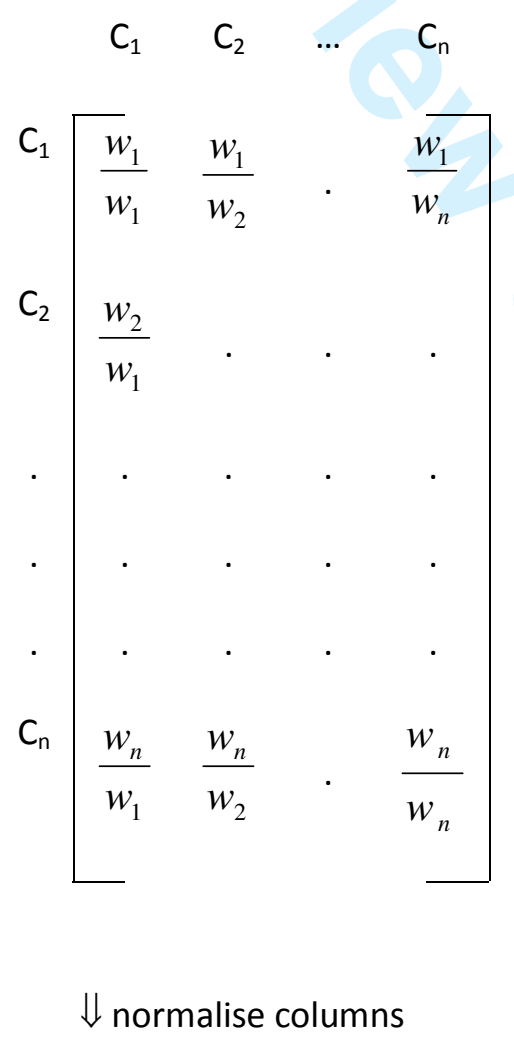


For each row $i$ in the resulting matrix above the average value is computed, such that $w_{i}=\frac{1}{n} \sum_{j} a_{i j}$.

Where $w_{i}$ is the weight of criterion $i$ in the weight vector $w=\left[w_{1}, w_{2}, \ldots, w_{n}\right]$ recovered from matrix A, with $n$ criteria, by finding a (non-trivial) solution to a set of $n$ equations with $n$ unknowns. This is achieved by solving the eigenvector problem: $A w=\lambda_{\max } w$. The sum of the weights is taken as equal to 1 , resulting in a unique non-trivial solution. Where $\lambda_{\max }$ is the principle eignevalue for the pairwise comparison matrix $A$.

One of the most practical issues in the AHP methodology is that it allows for slightly non-consistent pairwise comparisons. If all the comparisons are perfectly consistent, then the relation $\alpha_{i j}=\alpha_{i k} \alpha_{k j}$ should always be true for any combination of comparisons taken from the judgement matrix.

In practice, however, perfect consistency sparingly occurs. The pairwise comparisons in a judgement matrix are considered to be adequate if the corresponding consistency ratio (CR) is less than $10 \%$ (Saaty, 1980). First the consistency index (CI) will be estimated by computing $A w$ and approximating the maximum eigenvalue, $\lambda_{\max }$, using the following:

$$
\lambda_{\max }=\frac{1}{n} \sum_{i=1}^{n} \frac{i^{\text {th }} \text { entry in } A w}{i^{\text {th }} \text { entry in } w}
$$

Then, the CI value is calculated by using the formula: 
Next the consistency ratio (CR) is obtained by dividing the $\mathrm{Cl}$ by the Random Index (RI) as given in Table VI. The RI is the average value of $\mathrm{Cl}$ for randomly chosen entries in $\mathrm{A}$ (provided that $\alpha_{i i}=1$ and $\left.\alpha_{i j}=1 / \alpha_{j i}\right)$.

\section{[Table VI here]}

The synthesis step follows, after the alternatives have been compared with each other in terms of each one of the decision criteria and the individual priority vectors have been derived. The priority vectors become the columns of the decision matrix (not to be confused with the judgement matrices of the pairwise comparisons). The weights of importance of the criteria are also determined using pairwise comparisons. Therefore, given there is one goal, $m$ criteria and $n$ alternatives, the decision maker will create one $m \times m$ for the criteria and $m n \times n$ matrices for the alternatives. The $n \times n$ matrices will contain the results of $n(n-1) / 2$ pairwise comparisons between the alternatives. Finally, given a decision matrix the final priorities, denoted by $\mathrm{A}_{\mathrm{AHP}}^{i}$, of the alternatives in terms of all the criteria combined are determined according to the following formula:

$$
A_{A H P}^{i}=\sum_{j=1}^{n} a_{i j} w_{j}, \text { for } i=1,2,3, \ldots, m
$$

Clearly, the AHP is most efficiently applied when the total number of criteria and alternatives is not excessive. Several computer software packages are available to perform the AHP calculations, although the user is always obligated to input the pairwise comparison scores. For the purposes of the current work, the AHP has successfully been programmed into a spreadsheet workbook.

\section{The development of the suppliers evaluation methodology}

The illustrative example is for XYZ Co. as presented by Ordobadi (2009), and we use the Expert Choice Software package to translate the diagram shown in Figure (2) into a hierarchy as shown in Figure (3) below.

[Figure 3 here]

We then perform pair-wise comparison on each level with respect to the level above. For example, for the first level we will compare each factor (criterion) with the other as represented in Figure (4). 
[Figure 4 here]

Figure 5 shows how a questionnaire can be used to perform the pair-wise comparison. We use the Saaty's scale in Tale (5) and utilise the mapping of the fuzzy scale given in Table I into a linear AHP scale as shown n Table VII below.

[Table VII Here]

[Figure 5 here]

The same comparison is then carried out across the rest of the hierarchy. We use the Saaty's scale in Tale (5) and utilise the mapping of the fuzzy scale given in Table II into a linear AHP scale as shown $\mathrm{n}$ Table VIII below.

Once the pair-wise comparison is completed, the calculations of the overall suppliers ranking is obtained as shown in Figure (6).

[Figure 6 here]

There are three outputs that can be produced from the AHP model as shown below:

1) An overall ranking as shown in Figure (6) were the summation of rankings is equal to unity. This helps to in case one needs to allocate resources among alternative suppliers. It also helps in understanding how each supplier is compared to the other. Notice that in the fuzzy logic approach as shown in Table (IV) it is not possible to relate to the differences in the values of the crisp score.

2) A measure of Overall Inconsistency $f$ the decision maker's preferences which is a useful feedback for validation of consistency, as explained before. Overall consistency less than $10 \%$ is normally acceptable as a measure of consistent preferences.

3) A facility to perform sensitivity analysis (what-if analysis) which provides inforation about the causal relationships among the different factors. This capability can help us 
to explain and predict the different relationships among criteria and alternatives, a facility that is not offered by Ordoobadi (2009). This facility has been applied by Chen etal (2007) in the field of selection of suppliers in the airline industry. In the next section we demonstrate the sensitivity analysis.

\section{Results of Sensitivity Analysis:}

The results of sensitivity analysis can be shown in Figure (7), where the criteria are depicted as columns; for example the criterion of quality is more important than both cost and delivery and both are more important than cost. It also shows the performance of each of the three suppliers with respect to each of the criterion; for example with respect to Service (at the third column from the left) we notice that supplier C is better than B and B is better than A. Whereas with respect to Cost, supplier B is better than C and C is better than A. Also taking into consideration all the different criteria the overall ranking of suppliers is shown at the column titled 'Overall'.

\section{[Figure 7 here]}

Now what happens if the importance of criterion 'Service' is increased and 'Quality' decreased? We notice in Figure (8) that the overall ranking of suppliers will change into C better than $\mathrm{B}$ better than $\mathrm{C}$. This What-if analysis is very powerful as it can help us to predict the importance of suppliers in changing environments that will affect the importance of different criteria.

[Figure 8 here]

\section{Summary and suggestions for future research.}

In this paper we have shown that both techniques, AHP and FL, address the issue of the subjectivity inherent in human assessments that often cannot be expressed in pure numeric scales and requires linguistic expressions. To capture this subjectivity Ordoobadi (2009) has applied fuzzy logic that allows the decision makers to express their preferences/opinions in linguistic terms. However, in our paper we demonstrated how we can achieve the same objective by using AHP. Moreover, we demonstrated the capability to run a sensitivity analysis which helps to understand the causal relationships among the different factors. Moreover we presented how this capability can help us to explain and predict the different relationships among criteria and alternatives, a facility that is not offered by Ordoobadi (2009). In addition, we provided a measure that is able to capture the consistency of the decision maker's preferences. As with Ordoobadi's work the final scores are then translated into ranking of suppliers. However, in our approach we provide a single unit of scale that was not only capable of ranking suppliers but also provided us with an understanding of the difference in scale between different suppliers which can then help to allocate resources accordingly.

\section{Acknowledgement:}

The author is grateful to the reviewers for the valuable feedback comments received. 


\section{References}

1. Abdi, M.R. and A.W. Labib, 2003. A design strategy for Reconfigurable Manufacturing Systems (RMSs) using the Analytical Hierarchical Process (AHP): A case study, International Journal of Production Research, (IJPR), Vol. 41, No. 10, pp2273-2301.

2. Abdi, M.R. and A.W. Labib, 2004. A feasibility study of the tactical design justification for reconfigurable manufacturing systems (RMSs) using the fuzzy analytical hierarchical process (FAHP), International Journal of Production Research (IJPR), Vol 42 (15), pp 3055 - 3076.

3. Alvi and A.W. Labib, 2001. Selecting Next Generation Manufacturing Paradigms - An AHP Based Criticality Analysis, Proc. of IMechE, Journal of Engineering Manufacture - Part B, Vol 2 (5), pp 1773-1786 (December).

4. Chan, FTS, Chan, HK, Li, RW and Law, HCW, 2007, A decision support system for supplier selection in the airline industry, Proc. of IMechE, Part B: Journal of Engineering Manufacture, v221(4), pp. 741-758

5. Chan, F., Kumar, N., Tiwari, M., Lau, H., and Choy, K., 2008. Global supplier selection: a fuzzy-AHP approach, International Journal of Production Research, 46 (14), pp. 3825-3857.

6. Che, Z, 2009. A genetic algorithm-based model for solving multi-period supplier selection problem with assembly sequence, International Journal of Production Research (IJPR), Volume 48 (2), pp $425-435$.

7. Davidson, G., and A.W. Labib, 2003. Learning from failures: design improvements using a multiple criteria decision making process, Journal of Aerospace Engineering, Proceedings of the Institution of Mechanical Engineers Part G, Vol 217, pp 207-216.

8. Ho, W., Xu, X., Dey, P.K., 2010, Multi-criteria decision making approaches for supplier evaluation and selection: a literature review, European journal of operational research, v202, pp.16-24

9. Ishizaka A, Labib A, 2009. Analytic Hierarchy Process and Expert Choice: Benefits and Limitations, OR Insight, 22 (4), p. 201-220.

10. Jain, V., Wadhwa, S., Deshmukh, S., 2007. Supplier selection using fuzzy association rules mining approach, International Journal of Production Research (IJPR), 45 (6), 1323 - 1353.

11. Kannan, G., and Noorul Haq, A., 2007. Analysis of interactions of criteria and sub-criteria for the selection of supplier in the built-in-order supply chain environment, International Journal of Production Research (IJPR), 45 (17), 3831 - 3852.

12. Labib, A.W., and J. Shah, 2001. Management Decisions for a Continuous Improvement Process in Industry Using the Analytical Hierarchy Process, Journal of Work Study, Vol 50 (5), pp 189193.

13. Liu, P., and Zhang, X., 2010. Research on the supplier selection of a supply chain based on entropy weight and improved ELECTRE-III method, International Journal of Production Research (IJPR), 48 (5), 1626-1635.

14. Lee, C., and Ou-Yang, 2008. Development and evaluation of the interactive bidding strategies for a demander and its suppliers in supplier selection auction market, International Journal of Production Research (IJPR), 46 (17), 4827 - 4848.

15. Ordoobadi, S.M., 2009 "Development of a supplier selection model using fuzzy logic", Supply Chain Management: An International Journal, Vol. 14 Iss: 4, pp.314 - 327

16. Ravindran, A, Bilsel, R., Wadhwa, V., Yang, T., 2010. Risk adjusted multicriteria supplier selection models with applications, International Journal of Production Research (IJPR), Volume 48 (2), pp 405 - 425.

17. Sen, C., Seicuk, S., and Basligil, H., 2010. Pre-selection of suppliers through an integrated fuzzy analytic hierarchy process and max-min methodology, International Journal of Production Research (IJPR), 48 (5), 1603-1625.

18. Saaty TL, 1977. A Scaling Method for Priorities in Hierarchical Structures, Journal of Mathematical Psychology, 15 (1), pp. 57-68.

19. Saaty TL, 1980. The Analytic Hierarchy Process, McGraw-Hill International, New York, NY, U.S.A.

20. Saaty TL, 1994. Fundamentals of Decision Making and Priority Theory with the AHP, RWS Publications, Pittsburgh, PA, U.S.A. 
21. Sevkli, M., Koh S., Zaim, S., Demirbag, M., Tatoglu, E., 2007. An application of data envelopment analytic hierarchy process for supplier selection: a case study of BEKO in Turkey, International Journal of Production Research (IJPR), 45 (9), 1973 - 2003.

22. Talluri, S, Lee, J., 2010. Optimal supply contract selection, International Journal of Production Research (IJPR), Volume 48 (2), pp 437 - 465.

23. Vassoulla Vassou, A.W. Labib, Mark Roberts, 2006. A Decision Model for Junction Improvement Schemes, Proceedings of the Institution of Civil Engineers Transport, 159 (3), pp 127-134.

24. Wind Y \& Saaty TL, 1980. Marketing applications of the analytic hierarchy process, Management Science, Vol. 26 (7), pp. 641-658.

25. Yao, T. Jiang, B., Young, S., Talluri, S., 2010. Outsourcing timing, contract selection, and negotiation, International Journal of Production Research (IJPR) Volime 48 (2), pp 305-326.

26. Zhang, ZJ, Lei, N, Cao, K. and Ng, K., 2003 Evolution of supplier selection criteria and methods, European Journal of Operational Research, v4(1), pp. 335-342.

\section{Table(s) with caption(s) (on individual pages)}

Table I: The linguistic importance scale

\begin{tabular}{|l|l|}
\hline \multicolumn{1}{|c|}{ Linguistic Expressions for Importance } & Fuzzy Importance Scale \\
\hline Low importance (L) & $(0.0,0.0,0.2,0.4)$ \\
\hline Moderate importance (M) & $(0.2,0.4,0.4,0.6)$ \\
\hline High importance (H) & $(0.4,0.6,0.6,0.8)$ \\
\hline Very high importance (VH) & $(0.6,0.8,1.0,1.0)$ \\
\hline
\end{tabular}


Table II The linguistic performance scale. Adapted from Ordoobadi (2009).

\begin{tabular}{|l|l|}
\hline \multicolumn{1}{|c|}{ Linguistic Expressions for Performance } & \multicolumn{1}{|c|}{ Fuzzy Performance Scale } \\
\hline Poor performance (P) & $(0,0,2,4)$ \\
\hline Good performance $(\mathrm{G})$ & $(2,4,4,6)$ \\
\hline Very good performance (VG) & $(4,6,6,8)$ \\
\hline Excellent performance (EX) & $(6,8,10,10)$ \\
\hline
\end{tabular}


Table III Suppliers' performance ratings with respect to the selection criteria. Adapted from Ordoobadi (2009).

Selection criteria

\begin{tabular}{|l|l|l|l|}
\hline & Supplier A & Supplier B & Supplier C \\
\hline Customer reject rate & G & EX & VG \\
\hline $\begin{array}{l}\text { Quality control reject } \\
\text { rate }\end{array}$ & VG & VG & G \\
\hline Delivery lead time & P & G & P \\
\hline $\begin{array}{l}\text { Change in delivery } \\
\text { date }\end{array}$ & EX & P & VG \\
\hline Special requests & G & P & VG \\
\hline Reliability & P & G & EX \\
\hline Access & VG & EX & P \\
\hline Understanding & G & P & G \\
\hline Purchase price & P & G & G \\
\hline Logistics costs & VG & G & P \\
\hline
\end{tabular}


Table IV: Ranking of Supplies. Adapted from Ordoobadi (2009).

\begin{tabular}{|l|l|l|l|}
\hline & Fuzzy Scores & Crisp Scores & Rank \\
\hline Supplier A & $\begin{array}{l}(1.936,8.272, \\
12.144,31.648)\end{array}$ & 13.5 & 3 \\
& & & \\
\hline Supplier B & $\begin{array}{l}(3.12,11.2,15.488, \\
33.328)\end{array}$ & 15.78 & 2 \\
\hline Supplier C & $\begin{array}{l}(2.32,9.776,13.12, \\
32.56)\end{array}$ & 14.44 & 1 \\
\hline
\end{tabular}


Table V: Scale of relative importance (Saaty, 1980)

\begin{tabular}{|c|c|c|}
\hline $\begin{array}{l}\text { Intensity of } \\
\text { importance }\end{array}$ & Value description & Explanation \\
\hline 1 & Criterion $i$ and $\mathrm{j}$ are of equal importance & $\begin{array}{l}\text { Two activities contribute } \\
\text { equally to the objective }\end{array}$ \\
\hline 3 & Criterion $i$ is weakly more important than $j$ & $\begin{array}{l}\text { Experience and judgement } \\
\text { slightly favour one activity } \\
\text { over another }\end{array}$ \\
\hline 5 & Criterion $i$ is strongly more important than $j$ & $\begin{array}{l}\text { Experience and judgement } \\
\text { strongly favour one activity } \\
\text { over another }\end{array}$ \\
\hline 7 & Criterion $i$ is very strongly more important than $j$ & $\begin{array}{l}\text { An activity is strongly } \\
\text { favoured and its dominance } \\
\text { demonstrated in practice }\end{array}$ \\
\hline 9 & Criterion $i$ is absolutely more important than $j$ & $\begin{array}{l}\text { The evidence favouring one } \\
\text { activity over another is of the } \\
\text { highest possible order of } \\
\text { affirmation }\end{array}$ \\
\hline $2,4,6,8$ & Intermediate values between the two adjacent values & $\begin{array}{l}\text { When a compromise in } \\
\text { judgement is needed }\end{array}$ \\
\hline $\begin{array}{l}\text { Reciprocal } \\
\text { of above } \\
\text { (non-zero) }\end{array}$ & $\begin{array}{l}\text { If criterion } i \text { has one of the above non-zero numbers } \\
\text { assigned to it when compared with criterion } j \text {, then } j \\
\text { has the reciprocal value when compared with } i \text {. }\end{array}$ & \\
\hline
\end{tabular}


Table VI: RI values for different $\boldsymbol{n}$ values

\begin{tabular}{|l|c|c|c|c|c|c|c|c|c|c|c|c|c|c|}
\hline$n$ & 2 & 3 & 4 & 5 & 6 & 7 & 8 & 9 & 10 & 11 & 12 & 13 & 14 & 15 \\
\hline $\mathbf{R} \mathbf{I}_{\mathbf{n}}$ & 0.00 & 0.58 & 0.90 & 1.12 & 1.24 & 1.32 & 1.41 & 1.45 & 1.49 & 1.51 & 1.48 & 1.56 & 1.57 & 1.59 \\
\hline
\end{tabular}


Table VII: Mapping of fuzzy expressions for importance to the AHP scale

\begin{tabular}{|l|l|}
\hline $\begin{array}{c}\text { Pair-wise relationship of fuzzy } \\
\text { linguistic expressions for } \\
\text { importance as in Table (I) }\end{array}$ & $\begin{array}{c}\text { AHP equivalent values in the } \\
\text { questionnaire }\end{array}$ \\
\hline $\mathrm{VH}>\mathrm{H}$ & 2 \\
\hline $\mathrm{VH}>\mathrm{M}$ & 4 \\
\hline $\mathrm{VH}>\mathrm{L}$ & 6 \\
\hline $\mathrm{H}>\mathrm{M}$ & 2 \\
\hline $\mathrm{H}>\mathrm{L}$ & 4 \\
\hline $\mathrm{M}>\mathrm{L}$ & 2 \\
\hline
\end{tabular}


Table VIII: Mapping of fuzzy expressions for performance to the AHP scale

\begin{tabular}{|l|l|}
\hline $\begin{array}{c}\text { Pair-wise relationship of fuzzy } \\
\text { linguistic expressions for } \\
\text { performance as in Table (II) }\end{array}$ & $\begin{array}{c}\text { AHP equivalent values in the } \\
\text { questionnaire }\end{array}$ \\
\hline $\mathrm{EX}>\mathrm{VG}$ & 2 \\
\hline $\mathrm{EX}>\mathrm{G}$ & 4 \\
\hline $\mathrm{EX}>\mathrm{P}$ & 6 \\
\hline $\mathrm{VG}>\mathrm{G}$ & 2 \\
\hline $\mathrm{VG}>\mathrm{P}$ & 4 \\
\hline $\mathrm{G}>\mathrm{P}$ & 2 \\
\hline
\end{tabular}




\section{List of Figures Captions}

Figure 1: The criteria and sub criteria used for selection of suppliers, Ordoobadi (2009).

Figure 2: A typical AHP decision hierarchy

Figure 3: The AHP Model based on the case study provided by Ordoobadi (2009).

Figure 4: Criteria of the selection process.

Figure 5: The completed questionnaire for pair-wise comparison

Figure 6: The overall ranking of suppliers

Figure 7: Sensitivity Analysis

Figure 8: What if Analysis 


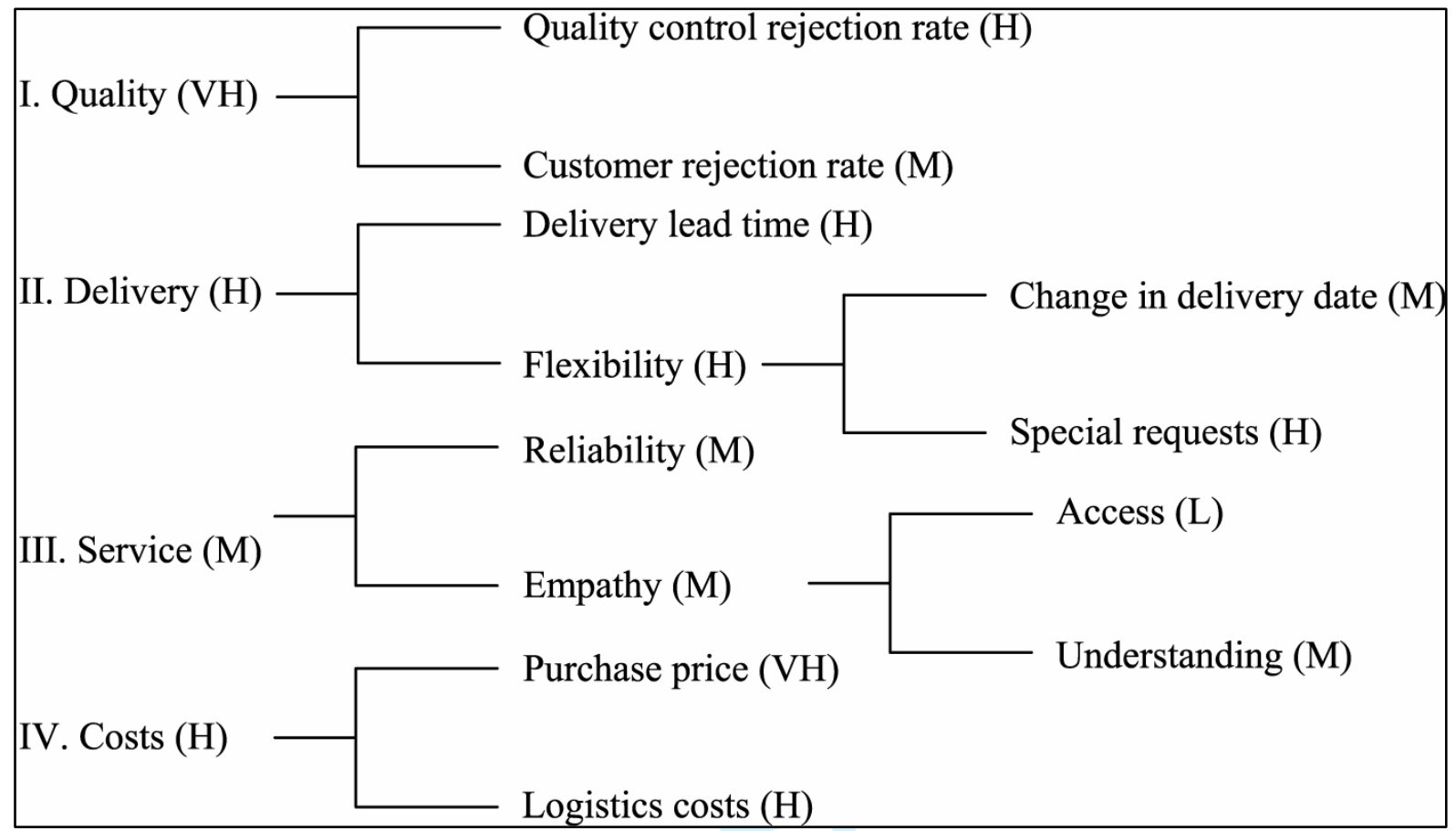




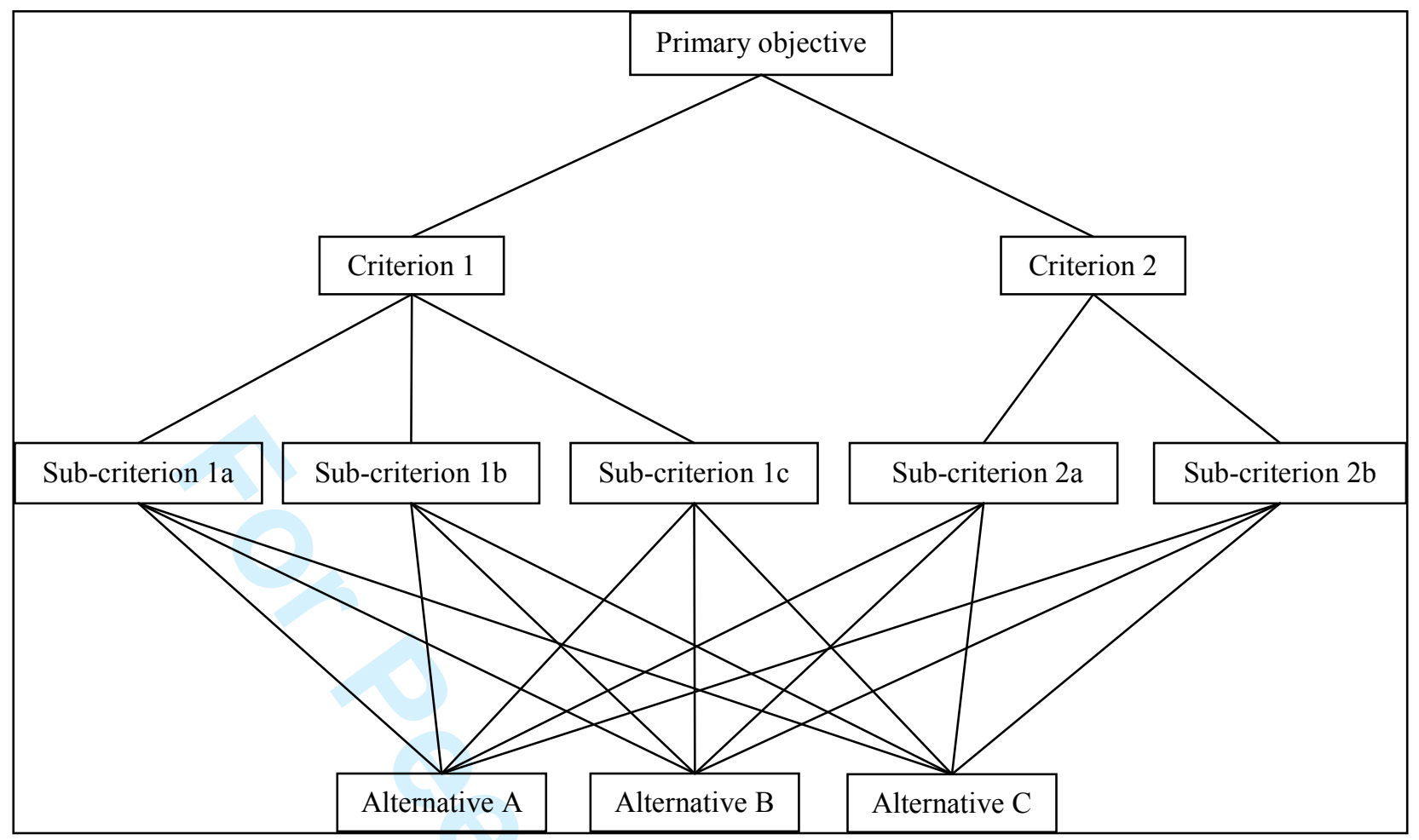




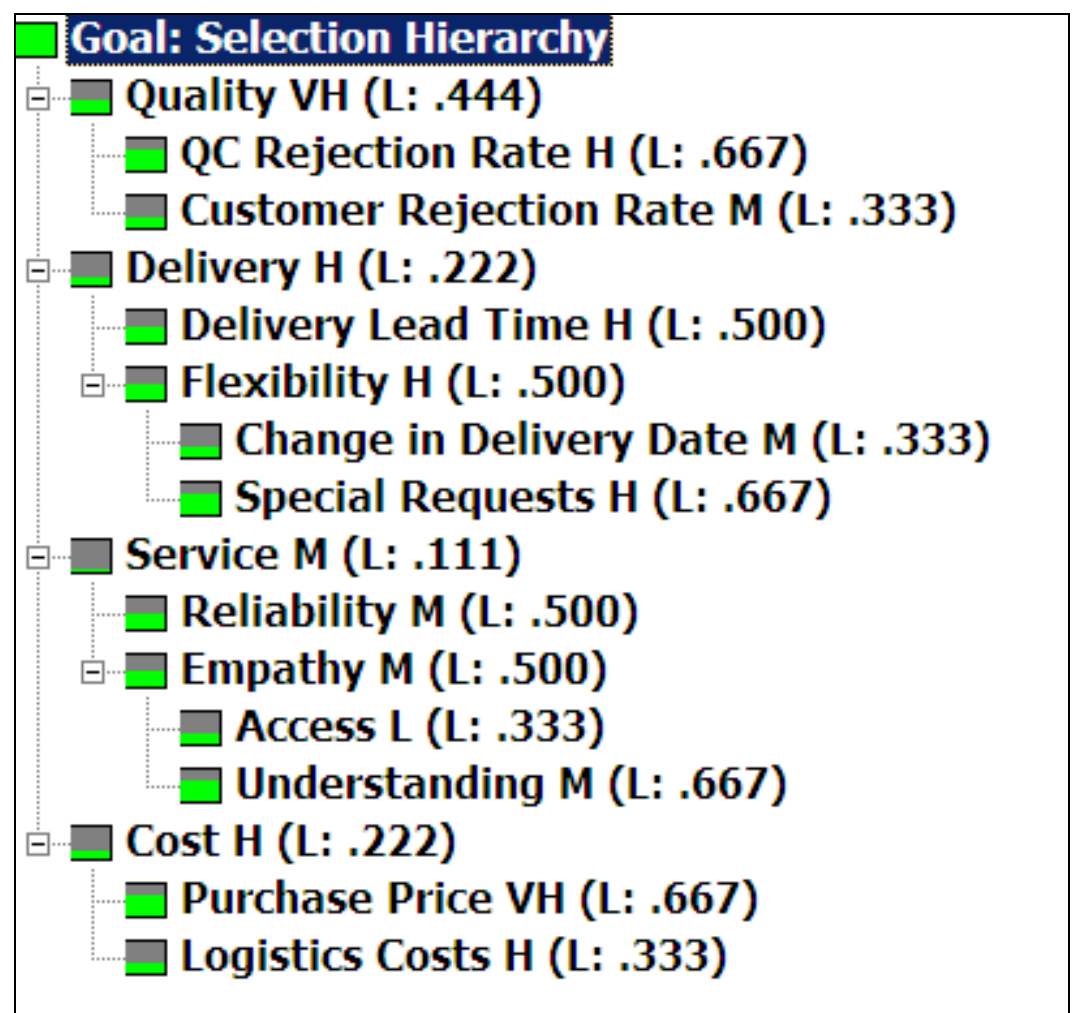




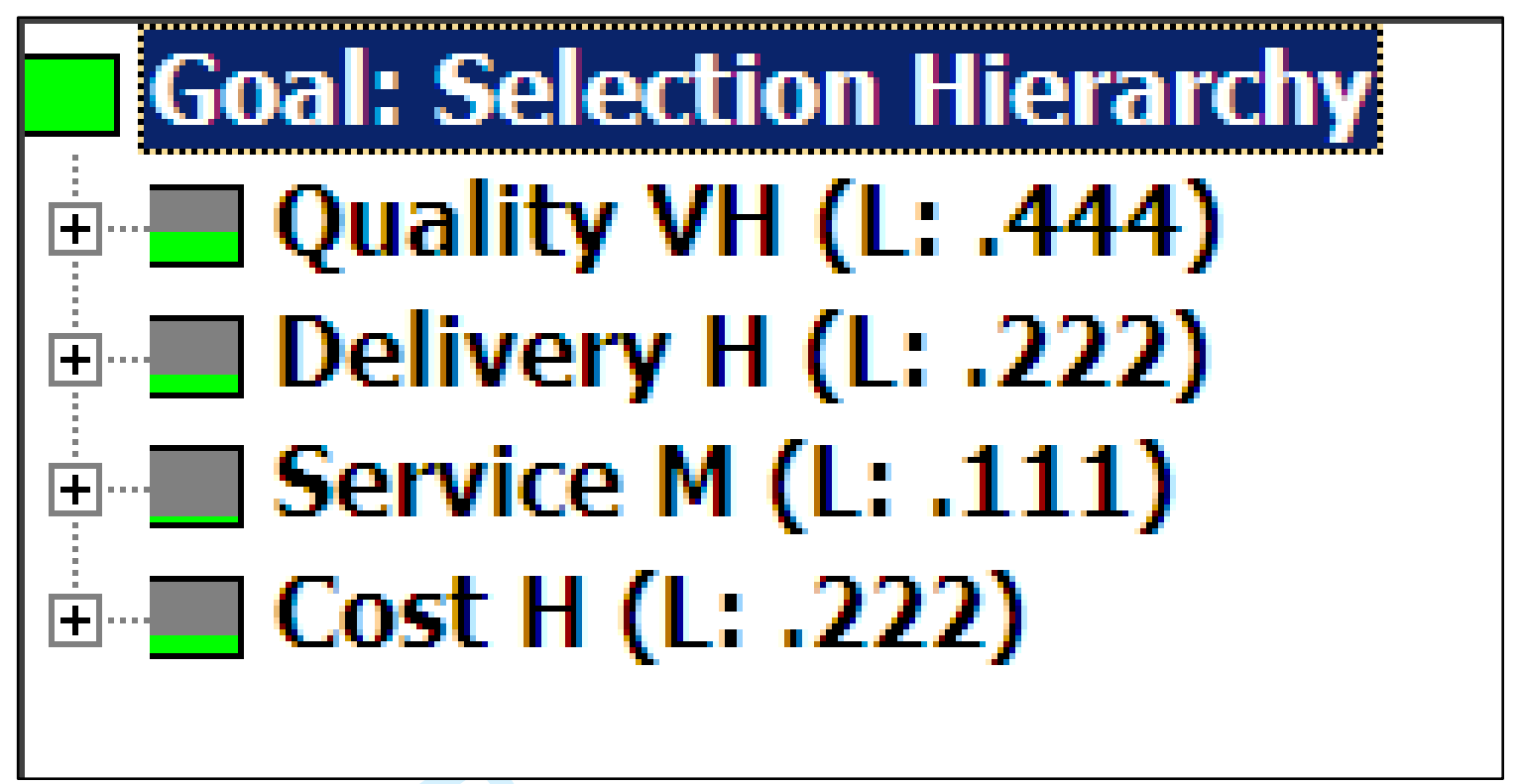




\section{? Questionnaire}

Ele Edit Assessment Go Help

\section{Compare the relative importance}

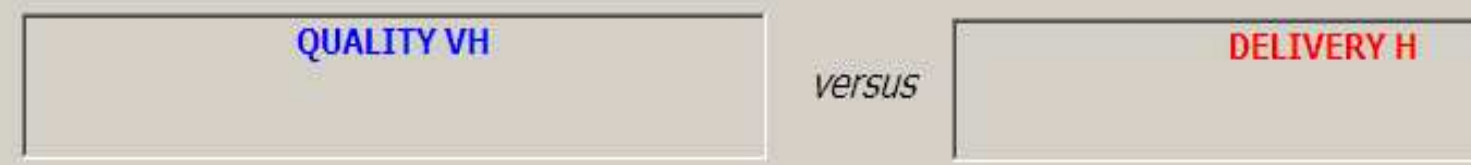

with respect to: Goal: Selection Hierarchy

\begin{tabular}{|c|c|c|c|c|c|c|c|c|c|c|c|c|c|c|c|c|c|c|}
\hline 1 Quality VH & 9 & 8 & 7 & 6 & 5 & 4 & 3 & $\frac{2}{2}$ & 1 & 2 & 3 & 4 & 5 & 6 & 7 & 8 & 9 & Delivery $\mathrm{H}$ \\
\hline 2 Quality VH & 9 & 8 & 7 & 6 & 5 & 4 & 3 & 2 & 1 & 2 & 3 & 4 & 5 & 6 & 7 & 8 & 9 & Service M \\
\hline 3 Quality VH & 9 & 8 & 7 & 6 & 5 & 4 & 3 & 2 & 1 & 2 & 3 & 4 & 5 & 6 & 7 & 8 & 9 & Cost H \\
\hline 4 Delivery $\mathrm{H}$ & 9 & 8 & 7 & 6 & 5 & 4 & 3 & 2 & 1 & 2 & 3 & 4 & 5 & 6 & 7 & 8 & 9 & Service M \\
\hline 5 Delivery $\mathrm{H}$ & 9 & 8 & 7 & 6 & 5 & 4 & 3 & 2 & 1 & 2 & 3 & 4 & 5 & 6 & 7 & 8 & 9 & Cost $\mathrm{H}$ \\
\hline 6 Service M & 9 & 8 & 7 & 6 & 5 & 4 & 3 & 2 & 1 & 2 & 3 & 4 & 5 & 6 & 7 & 8 & 9 & Cost $\mathrm{H}$ \\
\hline
\end{tabular}




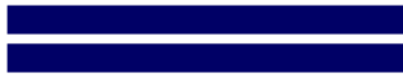




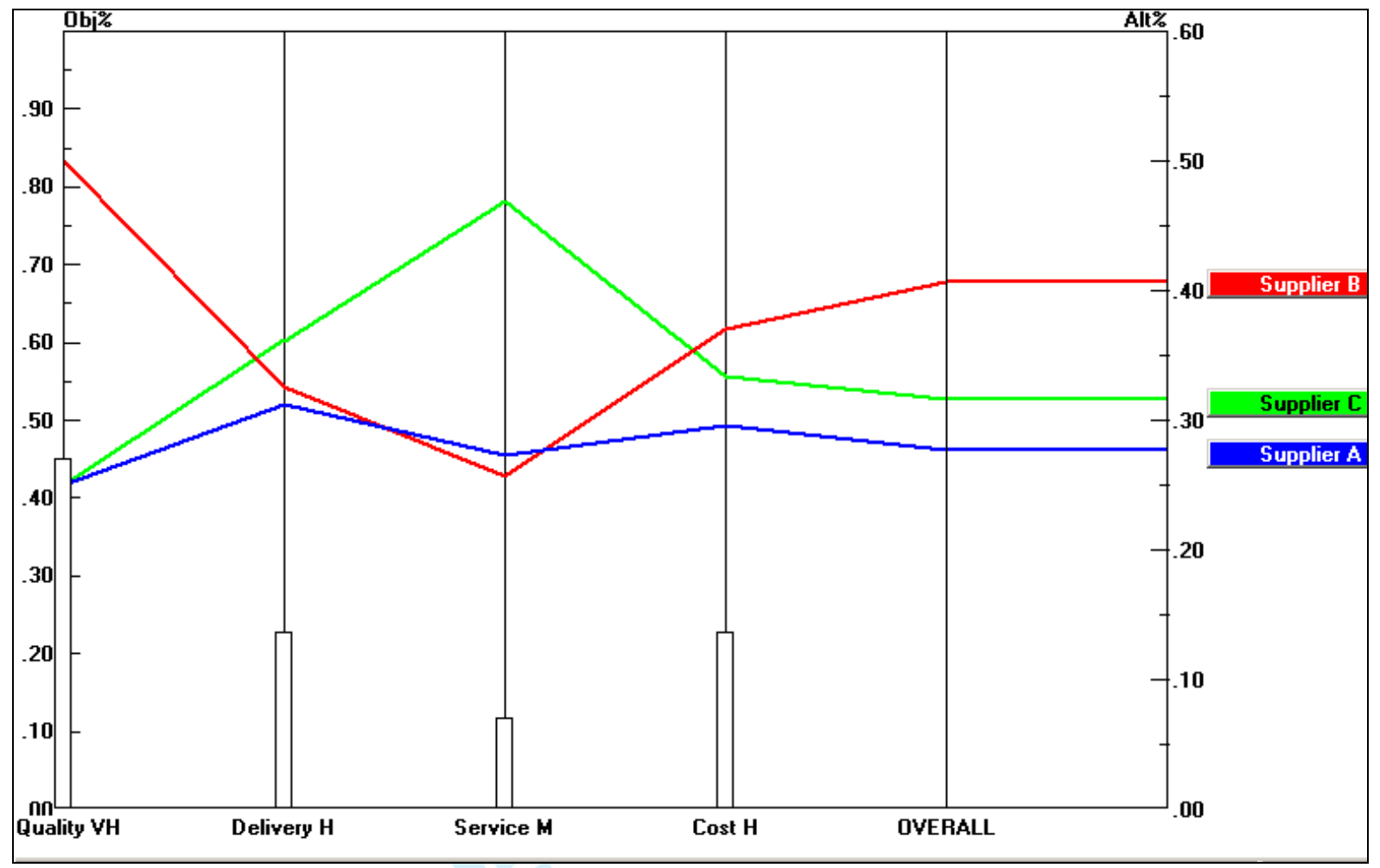




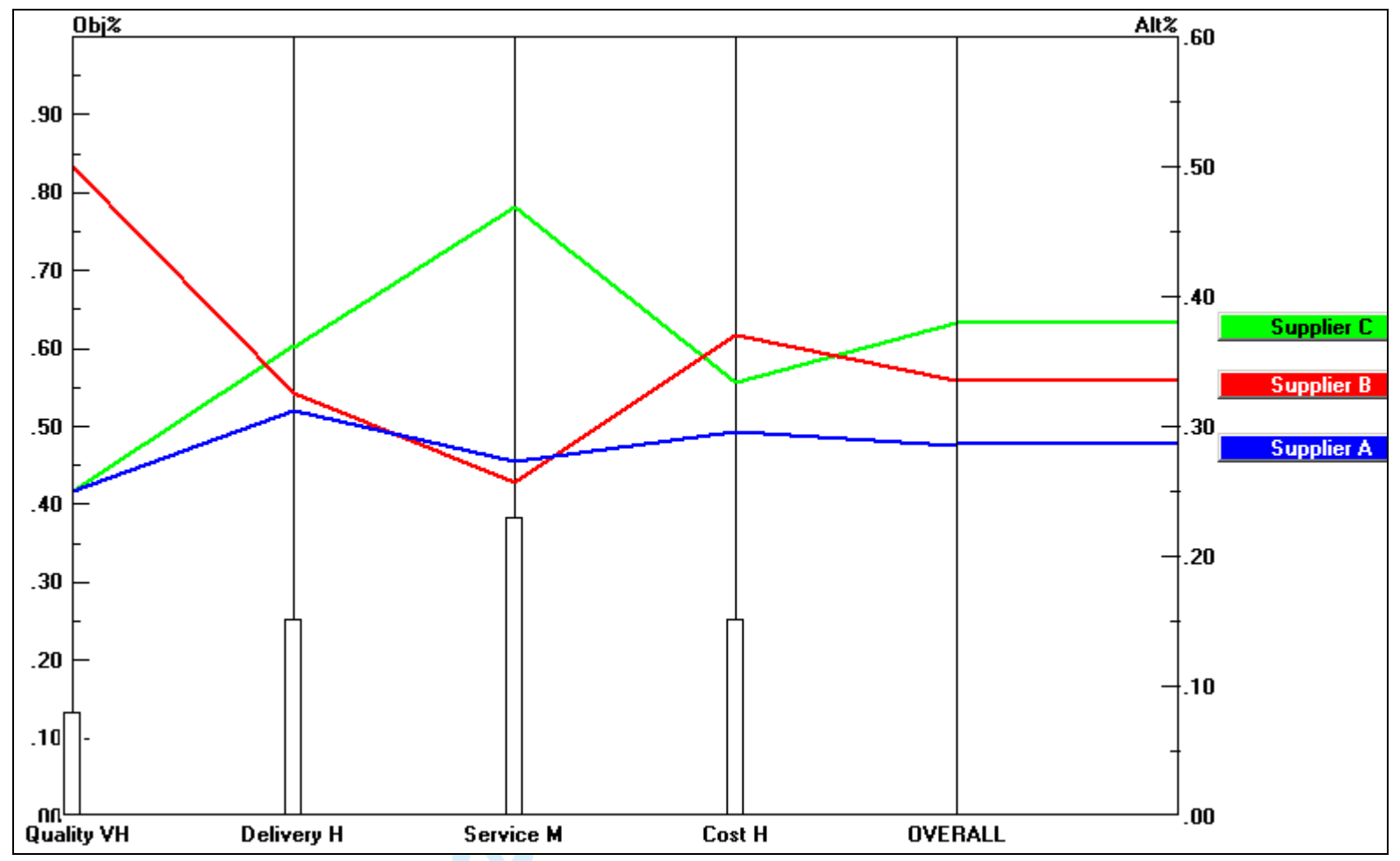

